\title{
Céline Béraud, Le métier de prêtre. Approche
} sociologique

Paris, Éditions de l'Atelier, 2006, 155 p.

Frédéric Gugelot

\section{OpenEdition}

\section{Journals}

Édition électronique

URL : http://journals.openedition.org/assr/5332

DOI : 10.4000/assr.5332

ISSN : 1777-5825

\section{Éditeur}

Éditions de l'EHESS

Édition imprimée

Date de publication : 1 juin 2007

Pagination : $97-251$

ISBN : 978-2-7132-2143-9

ISSN : 0335-5985

\section{Référence électronique}

Frédéric Gugelot, «Céline Béraud, Le métier de prêtre. Approche sociologique », Archives de sciences sociales des religions [En ligne], 138 | avril - juin 2007, document 138-6, mis en ligne le 11 septembre 2007, consulté le 10 décembre 2020. URL : http://journals.openedition.org/assr/5332 ; DOI : https:// doi.org/10.4000/assr.5332

Ce document a été généré automatiquement le 10 décembre 2020.

(C) Archives de sciences sociales des religions 


\section{Céline Béraud, Le métier de prêtre. Approche sociologique}

Paris, Éditions de l'Atelier, 2006, 155 p.

Frédéric Gugelot

1 Pourquoi devient-t-on prêtre aujourd'hui ? C. Béraud parvient à dévoiler les processus en cours dans les mutations du sacerdoce ecclésiastique et les tensions qui en résultent grâce à un choix de problématiques passionnant. Au moment où l'Église est confrontée à une crise de recrutement, les nouvelles façons de croire, l'aspiration à l'autonomie personnelle, elle s'interroge sur le « métier » de prêtre.

2 L'enquête de l'auteur permet de percevoir les tentatives pour redonner lustre et reconnaissance à la fonction de ceux qui s'engagent dans le sacerdoce. Ils réinventent la pratique et la légitimité du prêtre. Dans ce cadre, la vocation peut apparaître comme un accomplissement de soi qui légitime les sacrifices que ce statut exige. Dans le même temps, son rôle au sein de la communauté prend largement les traits d'un manager qui pousse à la professionnalisation de son exercice.

3 Les prêtres interrogés continuent à user de l'idée de sacerdoce pour insister sur la spécificité de leur choix professionnel. Leur mode de vie traduit la séparation marquée symboliquement par l'ordination avec le commun des mortels. Le don absolu à Dieu est promu comme un idéal sacrificiel. D'où un retour à l'idée d'un prêtre d'autel plus que d'un ministre de l'Évangile et une volonté de distinction, par exemple, vestimentaire. Mais l'auteure montre bien qu'il ne s'agit pas d'un retour en arrière, l'idéal sacerdotal promu par les nouveaux clercs est plus « recomposé que réactivé » (p. 28).

4 Les activités du prêtre sont aussi plurifonctionnelles. Trois émergent : la mise en forme rituelle, l'accompagnement, la ressource éthique. Prenons l'exemple de la première fonction : une certaine vision sacrale (le cérémoniaire), même parfois surnaturelle (le magicien), du prêtre revient, d'autant que progresse une division du travail nouvelle avec les laïcs. La diminution du nombre de clercs ayant conduit à une concentration sur les tâches religieuses, sa pratique a profondément évoluée. Il doit guider, coordonner les fidèles. La nécessaire mobilité du prêtre, qui passe de paroisse en paroisse, marque la fin de la civilisation paroissiale où un prêtre était attaché à une paroisse parfois pour 
toute sa vie. Elle contraint les communautés et les clercs à s'appuyer sur tout un personnel laïque que le prêtre doit animer. Or la formation initiale ne comprend pas celle de direction des ressources humaines.

5 Les interventions de Rome, le retour d'une conception «tridentine " n'apparaissent alors que comme une réponse à l'angoisse qui étreint les clercs face au rôle croissant des laïcs dans les tâches pastorales. L'autorité cléricale trouve dans ces trois fonctions sa légitimité mais recomposée et changeante, elle doit être sans cesse négociée.

6 La vocation de prêtre mue à l'aune de ses transformations. L'engagement radical et total se mâtine d'exigences nouvelles d'équilibre personnel, et donc de place aux loisirs, au repos, tant lieu de vie et lieu de travail sont confondus. Les prêtres revendiquent leur droit au bonheur personnel et au respect de leur espace privé. Certains insistent pour prendre des vacances, disposer d'un lieu personnel, rencontrer des amis. La solitude et la défection menacent le nouveau clerc. Car si la recherche de l'accomplissement personnel peut favoriser l'engagement dans le métier de prêtre, elle justifie aussi le renoncement quant l'échec est là.

7 La légitimité cléricale n'est plus fondée, le statut et l'autorité du prêtre non plus. Les jeunes clercs tentent donc une synthèse nouvelle, usant à la fois des éléments de la tradition qui justifient leur rôle et mobilisant d'autres registres tels la compétence. Mais se percevant comme à contre-courant d'une société où le don de soi ne se comprend plus, où l'argent devient le critère de l'existence sociale, ces hommes sont d'autant plus attachés à leur monopole sacramentel et au célibat que la quête de la distinction apparaît comme la source de légitimité sociale.

8 Ce livre est à la fois passionnant et captivant. Il ouvre bien des perspectives nouvelles dans l'approche de la crise du clergé de la fin du $\mathrm{xx}^{\mathrm{e}}$ siècle et des mutations en cours au sein du catholicisme. 